\title{
Erectile Dysfunction in a Cohort of Eugonodal Type 2 Diabetic Men Attending a Tertiary Healthcare Facility: Prevalence and Correlation with Testicular Volume
}

Chidiebele M. Ezeude $^{1 *}$, Afoma M. Ezeude ${ }^{2}$, Anthony C. Anyanwu ${ }^{3}$, Ogonna C. Oguejiofor ${ }^{1}$, Henry M. Nwankwo ${ }^{1}$, Adamu G. Bakari ${ }^{4}$

${ }^{1}$ Department of Internal Medicine, Nnamdi Azikiwe University Teaching Hospital, Nnewi, Anambra State, Nigeria.

${ }^{2}$ Department of Nursing Science, College of Health Sciences / School of Postgraduate Studies, Nnamdi Azikiwe University Awka, Nnewi Campus, Anambra State, Nigeria.

${ }^{3}$ Department of Internal Medicine, Federal Medical Centre, Owerri, Imo State, Nigeria.

${ }^{4}$ Department of Internal Medicine, Ahmadu Bello University Teaching Hospital, Zaria, Kaduna State, Nigeria.

*Corresponding Author: Chidiebele M. Ezeude, Department of Internal Medicine, Endocrinology, Diabetes and Metabolism Unit, Nnamdi Azikiwe University Teaching Hospital, P.M.B 5021, Nnewi. Anambra State, Nigeria. Phone: +2348036739065 E-mail: cm.ezeude@unizik.edu.ng, docchidi@yahoo.co.uk

Received date: September 29, 2020; Accepted date: October 05, 2020; Published date: November 26, 2020

Citation: Chidiebele M. Ezeude, Afoma M. Ezeude, Anthony C. Anyanwu, Ogonna C. Oguejiofor, Henry M. Nwankwo, Adamu G. Bakari (2020) Erectile Dysfunction in a Cohort of Eugonodal Type 2 Diabetic Men Attending a Tertiary Healthcare Facility: Prevalence and Correlation with Testicular Volume J. Endo and Dis; 4(1); DOI:10.31579/2640-1045/054

Copyright: () 2020, Chidiebele M. Ezeude, This is an open access article distributed under the Creative Commons Attribution License, which permits unrestricted use, distribution, and reproduction in any medium, provided the original work is properly cited.

\section{Abstract}

Background: Erectile dysfunction (ED) is a very common complication of diabetes mellitus. The prevalence of ED in diabetic patients, especially those with type 2 diabetes mellitus (T2DM) is very high compared with their non-diabetic counterparts. There are few studies on ED and its correlation with testicular volume in eugonadal type 2 diabetics globally and especially in subSaharan Africa.

Objective: To access the prevalence and correlation of ED with testicular volume in T2DM patients attending the diabetes outpatient clinic of Nnamdi Azikiwe University Teaching Hospital, Nnewi in South-eastern Nigeria.

Materials and Methods: This was a cross sectional prevalence study comprising 124 subjects with T2DM and 62 non diabetic controls. Data collection was done using a study protocol. Hospital Anxiety and Depression Scale (HADS) and the International Index of Erectile function (IIEF) questionnaires were used for diagnosis of anxiety/depression and erectile dysfunction respectively. Testicular volumes for the study subjects were estimated using Prader-orchidometer. Serum total testosterone, follicle stimulating hormone and luteinizing hormone levels were determined. Participants who had anxiety, depression or hypogonadism were excluded from the study. Statistical analysis was done using Statistical Package for Social Sciences (SPSS) version 20.

Results: The mean age of the subjects was $58.29 \pm 10.02$ while that of the controls was $56.48 \pm 10.58(\mathrm{P}=0.255) .48 .4 \%$ of the subjects had ED while $4.8 \%$ of the controls had erectile dysfunction $(\mathrm{P}<0.001)$. Of the subjects that had ED, 26.7\% had mild, $11.7 \%$ had moderate while $61.7 \%$ had severe erectile dysfunction. Severe ED was more associated with subjects $\left(\chi^{2}=7.230, \mathrm{P}=\right.$ 0.027). IIEF score has significant positive correlation with the mean testicular volume.

Conclusion: Prevalence of ED in men with T2DM in Nigeria is high and there is a significant positive correlation between ED and testicular volume in this group of subjects.

Keywords: erectile dysfunction; type 2 diabetes mellitus; eugonadal; hypogonadism; testicular volume; Prader orchidometer

\section{Abbreviation:}

ED: Erectile Dysfunction; T2DM: Type 2 Diabetes Mellitus; HADS: Hospital Anxiety and Depression Scale; IIEF: International Index of Erectile Function; FSH: Follicle Stimulating Hormone; LH: Luteinizing hormone, PDE5: Phosphodiesterase type 5, cGMP: Cyclic guanosine monophosphate: ARBs: Angiotensin receptor blockers, ACE-Is: Angiotensin converting enzyme inhibitors, CCBs: Calcium channel blockers,

\section{Introduction}

Erectile function is dependent on relaxation of the cavernous smooth muscle and its mechanism of action is mediated by nitric oxide (NO) [1]. Vasoconstrictions maintain the penis in the flaccid state.

Erectile dysfunction (ED) on the other hand is a persistent inability to achieve or maintain penile erection for satisfactory sexual intercourse [2]. It is one of the chronic complications of diabetes mellitus. 
The causes of erectile dysfunction fall into two main categories: organic and psychogenic [3]. Idiopathic and familial causes of ED are also encountered in clinical practice [4].

The key pathophysiologic mechanisms for ED revolve around organic (mainly vasculopathy and neuropathy) and psychogenic mechanisms (especially anxiety and depression) [3]. Diabetes causes ED mainly by causing vasculopathy and neuropathy. At Uyo, Niger Delta, Nigeria a study showed that $7.3 \%$ of cases of ED resulted from diabetes mellitus [5].

The burden of ED in subjects with DM, especially type $2 \mathrm{DM}$ is set to increase in the future since ED was found to precede the diagnosis of type $2 \mathrm{DM}$ in $36.3 \%$ of cases [6]. Diabetes mellitus is assuming a pandemic level globally. International Diabetes Federation (IDF) estimated that 425 million people had DM globally and that this figure is projected to rise to 629 million by the year 2045 [7]. Type 2 diabetes makes up about $90.0 \%$ of the cases of diabetes mellitus [8]. The predominant age of occurrence of DM is 40-59 years and worldwide estimate projects that in 2030 the greatest number of individuals with DM will be aged 45-65 years [9]. These are age ranges during which most men are sexually active and father children.

Erectile dysfunction in the setting of type $2 \mathrm{DM}$ is associated with a negative impact on emotional wellbeing and poor quality of life (QOL) [10]. There is increasing evidence that ED is a risk factor for cardiovascular diseases and early marker for coronary artery disease, which is the leading cause of mortality in patients with diabetes mellitus [11]. This is consistent with the inactivation of the anti-aging gene, Sirtuin-1. Sirtuin-1 repression is connected to the development of cardiovascular diseases and type 2 diabetes. It is equally connected to the development of ED, and treatments that activate Sirtuin-1, reverse ED in experimental rats [12].

The prevalence rate of ED among the general population in Nigeria was $19.8 \%$ [13], while that among type 2 DM patients was $87.8 \%$ and $71.1 \% 1$ $[14,15]$. The prevalence rate of ED in subjects with type $2 \mathrm{DM}$ was $67.9 \%$ in Ghana [16].

The prevalence of ED in patients with type 1 DM reported by Fedele et al and Maiorino et al was $26 \%$ and $37 \%$ respectively $[17,18]$.

The high prevalence of ED in men with diabetes underscores the need for an early diagnosis and treatment of this worrisome condition in this group of patients. The effective medical treatment of ED generally involves the use of the oral agent: phosphodiesterase type 5 (PDE5) inhibitors like sildenafil, tadalafil and vardenafil. The PDE5 is the primary phosphodiesterase in cavernosal smooth muscle responsible for degradation of cyclic guanosine monophosphate (cGMP) and its inhibitors are the first line agents in the treatment of erectile dysfunction [19]. Testosterone replacement therapy is also indicated in men with ED and concomitant hypogonadism. Recent guideline recommends testosterone supplementation for symptomatic men with morning total testosterone below $8 \mathrm{nmol} / \mathrm{L}$ [20]. The application of gene therapy as a viable treatment option for ED and other chronic pathological conditions appears promising in preclinical trials but the therapeutic approach still requires clinical studies in humans [21]. Yu et al found that resveratrol, an activator of Sirtuin-1 restores erectile function while Sahan et al noted that Melatonin, via Sirtuin-1 expression prevents deterioration of erectile function in streptozotocin-induced diabetic rats respectively [22,23].

There is paucity of available data on erectile dysfunction in type 2 DM subjects with normal total testosterone levels both locally and globally. Most studies done on the prevalence of ED in T2DM patients did not exclude hypogonadal subjects and this could have falsely increased the prevalence rates of type 2 diabetes-induced ED from these studies. The reason is that hypogonadism, having several other causes other than
T2DM is clearly associated with increased prevalence of ED because testosterone plays a major role in penile erection.

Also, to the best of our knowledge there is no published study in the subSaharan Africa that evaluated the correlation between ED and testicular volume among eugonadal T2DM subjects. Equally, studies have also shown that clinicians do not enquire about sexual dysfunction during diabetes consultations and that there is low prevalence of self-reported erectile dysfunction usually owing to the social stigma attached to it [24]. These made ED one of the most undiagnosed and yet treatable complications of diabetes mellitus. This study was aimed at addressing these gaps in knowledge, as well as answering these questions: is there a difference in the frequency of occurrence of ED in type 2 DM subjects, when compared with their non diabetic counterparts? Is there a correlation between ED (IIEF score) and testicular volume among T2DM subjects with normal serum total testosterone levels?

\section{Methods and materials}

\section{Research design}

This was a cross sectional hospital-based prevalence study comprising 124 subjects with type $2 \mathrm{DM}$ and a control group of 62 non diabetic subjects. All the study participants were classified based on their age into three groups: young, middle aged and elderly. Young age was taken as 18-44 years, middle age as 45-64 years and old age as 65 years and above [25].

\section{Study site and study population}

This study was carried out at the diabetes clinic of the Department of Internal Medicine of Nnamdi Azikiwe University Teaching Hospital (NAUTH), Nnewi, in Anambra State, south-eastern Nigeria. Nnewi is one of the major towns in Anambra State, and is well known for her industrial and commercial activities.

Nnamdi Azikiwe University Teaching Hospital, Nnewi is the major tertiary health center in Anambra State and serves the entire state and parts of the neighboring states of Imo, Delta, Enugu, Ebonyi and Abia states. The study population consisted of consenting male T2DM patients aged 30 years and above who presented consecutively to the NAUTH diabetes clinic for treatment. Age and sex-matched control subjects without diabetes were recruited from medical out-patient clinic for this study.

Exclusion criteria for the subjects included type 1 DM, a history of pelvic/penile trauma or surgery, psychiatric illness or antipsychotic medication use, hypogonadism, unfavourable penile anatomy for sexual act, urinary tract infection or severe illness including clinical finding of or history of cardiac disease. Those of the controls in addition, included diabetes mellitus or impaired fasting glucose [26].

Ethical clearance for the study was obtained from the ethical committee of the Nnamdi Azikiwe University Teaching Hospital, Nnewi and written informed consent was gotten from all the study participants.

\section{Data collection and procedure}

A total of 246 study participants were recruited at the beginning of this study. They comprised 172 subjects with type $2 \mathrm{DM}$ and 74 non diabetic controls. All the study participants were met individually by the primary investigator as they presented consecutively at the diabetes and the endocrine clinic respectively. Written consent was obtained from all the study participants. Each participant filled in the Hospital Anxiety and Depression Scale (HADS) questionnaire for the diagnosis of anxiety and depression [27]. The history of the use of antipsychotic drugs was obtained from all the participants [26]. None of the diabetic subjects and the controls had anxiety or depression and none was on antipsychotic medication.

The participants were scheduled by to come to the medical ward side laboratory between 8a.m and 9a.m on the appointed day, following an 
overnight fast of 8-14 hours and venous blood samples were drawn for fasting plasma glucose (FPG), serum total testosterone, follicle stimulating hormone (FSH) and luteinizing hormone (LH) assays. Also, the International Index of Erectile Function (IIEF) questionnaire was administered to all the study subjects [28]. The contents of both the IIEF and HADS questionnaires were translated into the local language (Igbo) for those who were not proficient in English language and their responses were filled in appropriately. The IIEF questionnaire and serum total testosterone were used for diagnosing erectile dysfunction and hypogonadism respectively [26]. A focused history was obtained and a detailed physical examination, including urogenital examination was done. Testicular volume (size) for each testis was estimated in $\mathrm{mL}$ for the T2DM subjects using Prader-orchidometer and the mean testicular volume calculated [29]. Erectile dysfunction was taken as a score of $\leq 25$ in the IIEF questionnaire: mild ED was a score of $17-25$, moderate ED was 11-16 and severe ED was a score 6-10 in IIEF questionnaire [28]. Hypogonadism was taken as morning serum total testosterone level < $280 \mathrm{ng} / \mathrm{dl}$ (9.70 nmol/l) [30]. Anxiety was defined by a score on the HADS Anxiety scale of $\geq 8$ and depression by a score of $\geq 8$ on the HADS Depression scale [27]. Normal adult testicular volume was taken as 12-25 $\mathrm{ml}[29]$.

A total of $48(27.90 \%)$ type 2 DM subjects had low serum testosterone level and were excluded from further participation in the study [26]. Similarly, $10(13.51 \%)$ non diabetic subjects had hypogonadism and were equally excluded from further participation in the study, while 2 declined further participation in the study. Overall, 124 type 2 DM subjects and their 62 non diabetic counterparts concluded the study.

\section{Statistical analysis}

Statistical analysis was performed using SPSS version 20 (SPSS Inc. Chicago, Illinois, USA). Descriptive statistics, which include frequency, percentages, means and standard deviation were used to summarize categorical and continuous variables. Associations between categorical variables were done using Chi square test and logistic regression. Student's t-test was used to compare means of continuous variables. Level of significance was set at $\mathrm{P}<0.05$. Results were presented in tables.

\section{Results}

A total of one hundred and eighty-six (186) subjects met the inclusion criteria and were studied. One hundred and twenty-four (124) of them had type 2 diabetes mellitus (subjects) while sixty-two (62) did not have diabetes mellitus (controls).

\section{Descriptive statistics}

Table 1 shows the descriptive statistics of base line characteristics in both type 2DM subjects and controls. Waist hip ratio (WHR), systolic blood pressure (SBP) and fasting plasma glucose (FPG) were significantly higher in subjects with type 2 DM compared with controls while IIEF score and serum Testosterone levels were significantly higher in control subjects compared with their counterparts with type 2 diabetes mellitus.

\begin{tabular}{|c|c|c|c|c|}
\hline Variables & Mean & SD) & t-test & p-value \\
\hline & $\begin{array}{l}\text { Type } 2 \text { DM Subjects } \\
(n=124)\end{array}$ & $\begin{array}{l}\text { Control Subjects } \\
(n=62)\end{array}$ & & \\
\hline Age (years) & $58.29(10.02)$ & $56.48(10.58)$ & 5.290 & 0.255 \\
\hline IIEF score & $26.77(19.40)$ & $59.19(16.22)$ & -12.018 & 0.000 \\
\hline Weight (kg) & $78.89(9.86)$ & $77.94(13.71)$ & -0.537 & 0.592 \\
\hline Height (m) & $1.70(0.08)$ & $1.72(0.07)$ & -1.79 & 0.076 \\
\hline BMI $\left(\mathrm{kg} / \mathrm{m}^{2}\right)$ & $26.89(4.22)$ & $26.66(3.40)$ & 0.393 & 0.695 \\
\hline $\mathrm{WC}(\mathbf{c m})$ & $91.15(9.86)$ & $90.68(8.77)$ & 0.329 & 0.743 \\
\hline WHR & $0.95(0.05)$ & $0.91(0.06)$ & 4.398 & 0.000 \\
\hline SBP $(\mathrm{mmHg})$ & $128.60(18.22)$ & $123.39(14.48)$ & 2.116 & 0.036 \\
\hline DBP (mmHg) & $84.16(12.64)$ & $81.71(9.93)$ & 1.445 & 0.150 \\
\hline Mean Testicular Volume (mL) & $21.94(3.19)$ & $22.10(3.14)$ & 0.327 & 0.744 \\
\hline FPG (mmol/L) & $9.01(3.19)$ & $5.37(0.61)$ & 12.245 & 0.000 \\
\hline Testosterone (nmol/L) & $19.01(11.02)$ & $25.27(12.13)$ & -3.422 & 0.001 \\
\hline FSH (mIU/mL) & $10.65(1.07)$ & $10.60(1.23)$ & 0.044 & 0.965 \\
\hline LH (mIU/mL) & $11.56(1.23)$ & $10.42(2.84)$ & 1.160 & 0.248 \\
\hline
\end{tabular}

BMI=Body Mass Index; DPB=Diastolic Blood Pressure; FPG=Fasting Plasma Glucose; FSH=Follicle Stimulating Hormone; IIEF=International Index of Erectile Function; LH=Luteinizing Hormone; SBP=Systolic Blood Pressure; WC=Waist Circumference; WHR=Waist to Hip Ratio.

\section{Table 1: Baseline Characteristics of Study Subjects}

\section{Prevalence of erectile dysfunction in subjects and controls}

Table 2 shows that $60(48.4 \%)$ of the subjects had erectile dysfunction while $3(4.8 \%)$ of the controls had erectile dysfunction. Erectile

dysfunction was significantly associated with subjects with type 2 diabetes $(\mathrm{P}<0.001)$. The subjects with type 2 diabetes were 18 times more likely to have erectile dysfunction than the controls $(\mathrm{OR}=18.437$, $95 \%$ C.I $=5.485-61.972)$.

\begin{tabular}{|l|l|l|l|l|l|}
\hline Erectile dysfunction & Subject n (\%) & Control n (\%) & P value & OR & 95\% C.I for OR \\
\hline Present & $60(48.4)$ & $3(4.8)$ & $<0.001$ & 18.437 & $5.485-61.972$ \\
\hline Absent & $64(51.6)$ & $59(95.2)$ & & & \\
\hline
\end{tabular}

Table 2: Prevalence of Erectile dysfunction in subjects and controls

\section{Age distribution of subjects and controls}

Table 3 shows that of the 124 subjects studied, 15 (12.1\%) were young, $73(58.9 \%)$ were of middle age and $36(29.0 \%)$ were elderly. For the controls 11(17.7\%) were young, $34(54.8 \%)$ were of middle age and 17 (27.4\%) were elderly. There was no statistically significant difference between the different age groups in both the subjects and controls $\left(\chi^{2}=\right.$ $1.097, \mathrm{P}=0.578$ ).

Table 4 shows that the mean age of the subjects was $58.29 \pm 10.02$ while that of the controls was $56.48 \pm 10.58(\mathrm{P}=0.255)$. The difference was not statistically significant. 


\begin{tabular}{|l|l|l|l|}
\hline Age group & Subject n (\%) & Controln (\%) \\
\hline Young $(\mathbf{3 0}-\mathbf{4 4})$ & $15(12.1)$ & $11(17.7)$ \\
\hline Middle aged (45-64) & $73(58.9)$ & $34(54.8)$ \\
\hline Elderly $(\geq \mathbf{6 5})$ & $36(29.0)$ & $17(27.4)$ \\
\hline Total & $\mathbf{1 2 4}(\mathbf{1 0 0 . 0})$ & $\mathbf{6 2}(\mathbf{1 0 0 . 0})$ \\
\hline
\end{tabular}

$\chi^{2}=1.097, \mathrm{P}=0.578$

Table 3. Age distribution of subjects and controls

\begin{tabular}{|l|l|l|l|l|}
\hline Variables & \multicolumn{1}{|c|}{ Mean (SD) } & t-test & p-value \\
\hline & $\begin{array}{l}\text { Type 2 DM Subjects } \\
(\mathbf{n = 1 2 4})\end{array}$ & $\begin{array}{l}\text { Control Subjects } \\
(\mathbf{n}=\mathbf{6 2})\end{array}$ & & \\
\hline Age (years) & $58.29(10.02)$ & $56.48(10.58)$ & 5.290 & 0.255 \\
\hline
\end{tabular}

Table 4. Mean age of subjects and control

Prevalence of erectile dysfunction among the various age groups in the subjects

Table 5 shows that more individuals in the young and elderly age groups had ED compared with those without ED, although this was not statistically significant $(\mathrm{P}=0.309)$. Reverse was the case with the middle age group as those without ED were more than those that had erectile dysfunction. This was equally not statistically significant $(\mathrm{P}=0.309)$.

\begin{tabular}{|l|l|l|l|l|}
\hline \multicolumn{5}{|c|}{ N (\%) } \\
\hline Age Group & \multicolumn{2}{|c|}{ Type 2 DM Subjects (N=124) } & $\chi^{\mathbf{2}}$ & p-value \\
\hline & ED present (n=60) & ED Absent (n=64) & & \\
\hline Young & $9(15.0)$ & $6(9.4)$ & 2.35 & 0.309 \\
\hline Middle aged & $30(50.0)$ & $43(67.2)$ & & \\
\hline Elderly & $21(35.0)$ & $15(23.4)$ & & \\
\hline
\end{tabular}

Table 5. Prevalence of erectile dysfunction among the various age groups in the subjects

\section{Degree of erectile dysfunction among subjects and controls}

Table 6 shows that out of 60 subjects with erectile dysfunction, 16 $(26.7 \%)$ had mild, $7(11.7 \%)$ had moderate while $37(61.7 \%)$ had severe erectile dysfunction. In the same vein, out of 3 controls with erectile dysfunction, none had mild, $2(66.7 \%)$ had moderate while $1(33.3 \%)$ had severe erectile dysfunction. Severe erectile dysfunction was more associated with the subjects $\left(\chi^{2}=7.230, \mathrm{P}=0.027\right)$.

\begin{tabular}{|c|l|l|l|l|}
\hline Degree of Erectile dysfunction & Subject n (\%) & Control n (\%) & $\boldsymbol{\chi}^{\mathbf{2}}$ & P value \\
\hline Mild & $16(26.7)$ & $0(0.0)$ & 7.230 & 0.027 \\
\hline Moderate & $7(11.7)$ & $2(66.7)$ & & \\
\hline Severe & $37(61.7)$ & $1(33.3)$ & & \\
\hline Total & $60(100.0)$ & $3(100.0)$ & & \\
\hline
\end{tabular}

Table 6. Degree of erectile dysfunction among subjects and controls

\section{Mean comparison of age between subjects and controls with and without erectile dysfunction}

Subjects with erectile dysfunction were significantly older, with mean age of $61.00 \pm 10.79$ when compared with those without erectile dysfunction with mean age of $55.77 \pm 8.55 ;(\mathrm{t}=3.002, \mathrm{P}=0.003)$.

Controls with erectile dysfunction had a significantly higher mean age of $73.00 \pm 3.46$ when compared with that of those without erectile dysfunction with mean age of $55.64 \pm 10.13(\mathrm{t}=2.939, \mathrm{P}=0.005)$.

\section{Correlation of IIEF score with mean testicular volume, serum testosterone, FSH and LH concentrations among type 2 diabetic subjects}

Table 7 shows the correlation of IIEF score with mean testicular volume, serum testosterone, FSH and LH in the study subjects with type 2 diabetes mellitus. International Index of Erectile Function score positively correlated with each of mean testicular volume and serum testosterone but negatively correlated with each of serum FSH and LH. The association of IIEF score with mean testicular volume was the strongest and this relationship was statistically significant.

\begin{tabular}{|l|l|l|l|l|l|}
\hline \multicolumn{5}{|l|}{ Pearson Correlation Coefficient, $\mathbf{r}$} \\
\hline & Type 2 DM Subjects (N=124) & \multicolumn{1}{l|}{} \\
\hline & Mean testicular volume & Testosterone & FSH & LH & IIEF Score \\
\hline Mean testicular volume & 1.000 & & & & \\
\hline Testosterone & $0.200^{*}$ & 1.000 & & & \\
\hline FSH & -0.067 & -0.005 & 1.000 & & \\
\hline LH & -0.108 & -0.038 & $0.955^{*}$ & 1.000 & \\
\hline IIEF Score & $0.183^{*}$ & 0.023 & -0.097 & -0.165 & 1.000 \\
\hline
\end{tabular}

*Statistically Significant

Table 7: Correlation of IIEF Score with Mean Testicular Volume, Serum Testosterone, FSH and LH Concentrations among Type 2 Diabetic Subjects. 


\section{Discussion}

\section{Prevalence of erectile dysfunction in patients with type 2 diabetes mellitus}

This was a cross sectional hospital-based study which aimed at assessing the prevalence, pattern and correlation of erectile dysfunction with testicular volume in subjects with type 2 diabetes mellitus. Non diabetic controls were also studied and compared with the subjects with type 2 diabetes mellitus.

This study showed that the prevalence of ED among subjects with T2DM was $48.4 \%$ while that of the non-diabetic controls was $4.8 \%(\mathrm{P}<0.001$, $\mathrm{OR}=18.437,95 \%$ C.I for $\mathrm{OR}=5.485-61.972$ ). The result is similar to other studies done on erectile dysfunction in patients with T2DM globally $[31,32]$.

In this study, ED is about eighteen times more likely to occur in type 2 diabetic subjects compared to their non diabetic counterparts. This significant association between ED and type 2 DM re-emphasizes an already established fact. The prevalence of ED in type 2 DM subjects from this study is lower than what was observed in studies of ED in type 2 diabetes in other parts of Nigeria. For example, a prevalence of $87.8 \%$ was reported in Jos and $71.1 \%$ in Ile-Ife $[14,15]$. Also, the prevalence of ED in diabetic subjects was $72.7 \%$ in Ibadan [33]. These other studies equally had middle aged and elderly men among their study participants, but unlike this study, did not exclude subjects who had low testosterone level and this could account for the wide margin between the prevalence of ED in this study and their own. This is in view of the fact that aging men are prone to hypogonadism, causing age-induced erectile dysfunction [34].

It is also possible that this study by excluding all subjects with hypogonadism, also excluded some young and middle-aged men who may have had ED resulting from type 2 DM induced hypogonadism [35]. This is in view of the fact that Ogbera et al reported that the prevalence of symptomatic hypogonadism in subjects with type $2 \mathrm{DM}$ in Lagos, Nigeria was $36.0 \%$ [36].

The study done in Jos in addition had a small sample size of 66 [14]. The mean age of their subjects as $56.0 \pm 8.8$ [14] and is comparable to that of this study (58.29 \pm 10.02 years). Similarly, Adebusoye et al in Ibadan studied only 33 diabetic subjects [33]. The small sample sizes could also account for the higher prevalence rates reported by these studies.

The prevalence rate of erectile dysfunction in type 2 DM subjects in Ghana was $67.9 \%$ [16]. This study equally did not exclude type 2 DM subjects with hypogonadism.

Higher prevalence rates of ED in type $2 \mathrm{DM}$ subjects were also found in Italy $(60.0 \%)$ and Iran $(59.5 \%)[31,32]$. These studies did not exclude type 2 DM subjects who had low serum testosterone levels.

An equally plausible reason for the lower prevalence of ED from our study could be from the fact that many of our type 2 DM subjects were equally hypertensive. Most of study subjects were on angiotensin receptor blockers (ARBs), angiotensin converting enzyme inhibitors (ACE-Is) and or calcium channel blockers (CCBs) either as antihypertensive or antiproteinuric medication. Angiotensin receptor blockers had been reported in a study to exhibit a beneficial effect on erectile function while CCBs and ACE-Is seemed to have neutral effect [37].

Another possible reason for the higher prevalence rates in these studies could be due to the differences in methodology they adopted and the characteristics of the population they studied. Another important finding from this work is that severe ED was commonest (61.7\%) among the type 2 diabetic subjects with ED, followed by mild ED (26.7\%) and moderate ED (11.7\%). While moderate ED (66.7\%) was commonest among the non-diabetic controls. This finding is similar to that of Ugwu et al [15]. Severe ED was commonest among his T2DM subjects (33.6\%), followed by mild ED $(19.1 \%)$ and lastly moderate ED (18.4\%).

The prevalence rate of ED in patients with type $1 \mathrm{DM}$ was $26 \%$ and $37 \%$ respectively $[17,18]$. These two prevalence rates are close to that from this study and is far less than those from other studies that did not exclude hypogonadal type $2 \mathrm{DM}$ patients. Hypogonadism is commoner in men with type $2 \mathrm{DM}$ compared to those with type $1 \mathrm{DM}$ largely because obesity is more in type 2 diabetes patients [38]

\section{Correlation of IIEF scores with mean testicular volume, serum testosterone, and FSH and LH concentrations among type 2 diabetic subjects.}

This study showed that there was positive correlation between the mean testicular volume and the IIEF score in type 2 diabetic subjects. There was also a positive correlation between serum testosterone level and IIEF score, although this was not statistically significant. The International Index of Erectile Function score on the other hand had negative, nonsignificant correlation with FSH and LH. This means that both the mean testicular volume and serum testosterone levels expectedly decreased with decreasing IIEF score. This agrees with the finding of Ugwu et al [15], that testosterone deficiency was significantly associated with erectile dysfunction in type 2 diabetic subjects.

From this study also FSH and LH increased with a decreasing IIEF score giving a biochemical picture of "hypergonadotropic eugonadism". El Saghier et al found normal FSH and LH and low serum testosterone level (hypogonadotropic hypogonadism) in Egyptian type 2 diabetic subjects while Talukder et al found that low FSH and LH (hypogonadotropic hypogonadism) was commoner among Bangladesh men with type $2 \mathrm{DM}$ and hypogonadism $[39,40]$. The above two studies unlike the index study evaluated type 2 diabetic subjects with low serum testosterone level.

The finding of decreasing testicular volume with decreasing IIEF score in this study agrees with that of Talukder et al that testicular volume was significantly lower in hypogonadal men with type $2 \mathrm{DM}$ compared to their eugonadal counterparts [40].

\section{Conclusion}

1. The prevalence of erectile dysfunction in type $2 \mathrm{DM}$ patients in Nnewi, south-eastern Nigeria is $48.4 \%$.

2. The prevalence of ED in males with type 2 diabetes mellitus is about eighteen times higher when compared with their counterparts without diabetes mellitus.

3. There is significant positive correlation between IIEF scores and mean testicular volumes in the subjects with type 2 diabetes mellitus.

4. There is an urgent need for a routine screening for, early diagnosis of and prompt treatment of ED in type 2 diabetic subjects.

\section{Recommendations}

1. In view of the high prevalence of ED in type $2 \mathrm{DM}$ patients in this study, it is recommended that, physicians and other health care professionals who treat diabetic patients would look out for ED and other chronic complications of DM in our diabetic patients routinely and take appropriate measures to tackle them.

2. In view of the wide variation in the prevalence of ED in subjects with type $2 \mathrm{DM}$ from various studies, more studies on this very important and common complication of diabetes are needed to resolve this.

\section{Limitations of the study}

1. International Index of Erectile Function (IIEF) questionnaire that was used in this study is a self-report diagnostic tool. Its interpretation to the patients who do not understand English language may have reduced the accuracy of the responses given. 
2. The Hospital Anxiety and Depression Scale questionnaire also used in the study is a self- report diagnostic tool. Its interpretation to the patients who do not understand English language as well as the socio-cultural implications of some of the questions in our setting could make some of the responses very subjective.

3. Elderly type $2 \mathrm{DM}$ subjects were also enrolled and participated in this study and aging is a known risk factor for erectile dysfunction.

4. Patients who had both type $2 \mathrm{DM}$ and hypertension, were included in the study because their exclusion would have limited the number of subjects for the study. These patients were either on angiotensin receptor blockers (ARBs), angiotensin converting enzyme inhibitors (ACE-Is) and or calcium channel blockers (CCBs). ARBs exhibit a beneficial effect on erectile function, while ACE-Is and CCBs have neutral effect.

5. Most of our study subjects who smoked tobacco or consumed alcohol had quitted prior to the commencement of this study mainly due to medical advice. The few subjects who still smoked tobacco and drank alcohol as at the time of the study may have influenced the outcome of this study because current smoking and heavy alcohol consumption were found to be associated with erectile dysfunction in both the diabetic subjects and in the general population.

\section{Conflict of interest}

The authors have no competing interest.

\section{Funding}

The authors did not receive any financial assistance for the research.

\section{References}

1. Melmed S, Polonsky KS, Larsen PR, Kronenberg HM. (2011) Williams textbook of Endocrinology $12^{\text {th }}$ Ed. Philadelphia: Elsevier Saunders; Chapter 20. 781-782.

2. NIH Consensus Conference. Impotence. NIH Consensus Development Panel on Impotence. JAMA. 1993. 270: 83-90.

3. Neelima VC, Edelman SV. (2001). Diabetes and erectile dysfunction. Clinical diabetes. 15: 63-71.

4. Takure AO, Adebayo SA, Okeke LI, Olapade-Olaopa EM, Shittu OB. (2016) Erectile dysfunction among men attending Surgical Outpatients Department in a Tertiary Hospital in South-Western Nigeria. Nigerian J. of Surgery; 22: 32-36.

5. Idung AU, Abasiubong F, Ukott IA, Udoh SB, Unadike BC. (2012) Prevalence and risk factors of Erectile Dysfunction in Niger Delta region, Nigeria. Afr Health Sci. 12: 160-165.

6. Chinenye S, Uchenna DI, Unachukwu CN, Ogbera AO, Ojule AC. (2008) The pattern of diabetes mellitus in River State, Nigeria. Nigerian Endocrine Practice. 2: 87-93.

7. International Diabetes Federation (IDF). (2017) Diabetes Atlas $8^{\text {th }}$ Ed.

8. World Health Organization. (1999) Definition, diagnosis and classification of diabetes mellitus and its complications. WHO/NCD/NCS 99. Geneva. WHO; pp 1-58.

9. Longo DL, Fauci AS, Kasper DL, Hauser SL, Jameson JL et al. (2012). Harrison's Principle of Internal Medicine $18^{\text {th }}$ ed. New York: Mcgraw Hill. Chapter 344.

10. De Berardis G, Francoisi M, Belfiglio M, Di Nardo B, Greenfield S et al (2002). Erectile Dysfunction and Quality of Life in Type 2 Diabetic Patients. Diabetes Care. 25: 284-291.

11. Montorsi P, Ravagnani PM, Galli S, Briganti A, Salonia A et al. (2005) Association of erectile dysfunction and coronary artery disease : a case report study. J Sex Med. 2: 575-582.
12. Martins IJ. (2016) Anti-Aging Genes Improve Appetite Regulation and Reverse Cell Senescence and Apoptosis in Global Populations. Advances in Aging Research, 5 (01) 9 - 26.

13. Yovwin DG, Imarhiagbe FA, Obazee EM, Oguike TC. (2015). Erectile dysfunction in a Sub-Saharan African population: Profile and Correlates in a tertiary care hospital. Sahel Med J. 18: 116-120.

14. Adegite A, Aniekwensi E, Ohihon A. (2009). The prevalence of erectile dysfunction and its socio-demographic and life style correlates among male type 2 diabetics in Jos, Nigeria. In: Abayasekara R, Abraham P, Ahlquist J, Atkin S, Carson M, Clayton $\mathrm{P}$ et al, editors. Endocrine Abstract 2009. Presented at the Society for Endocrinology BES 2009, March 16-19; Harrogate, UK. Bioscientifica Ltd: Bristol, UK. P. 157.

15. Ugwu T, Ezeani I, Onung S, Kolawale B, Ikem R. (2016). Predictors of Erectile Dysfunction in Men with Type 2 Diabetes Mellitus Referred to a Tertiary Healthcare Centre. Advances in Endocrinology Volume 2016, Article ID 9753154.

16. Owiredu W, Amidu N, Alidu H, Sarpong C, Gyasi-Sarpong CK. (2011). Determinants of Sexual dysfunction among clinically diagnosed diabetic patients. Reprod Biol Endocrinol. 9: 70.

17. Fedele D, Bortolotti A, Coscelli C, Santeusanio F, Chatenoud L, Colli E et al. (2000) Erectile dysfunction in type 1 and 2 diabetics in Italy. Int J Epidemiol. 29: 524-531.

18. Maiorino M, Bellastella G, Della Volpe E, Casciano O, Scappaticcio L, Cirillo P et al. (2016) Erectile dysfunction in young men with type 1 diabetes. Int J Impot Res. 29 (1): 17 - 22.

19. Melmed S, Polonsky KS, Larsen PR, Kronenberg HM. (2011) Williams textbook of Endocrinology $12^{\text {th }}$ Ed. Philadelphia: Elsevier Saunders. Chapter 20:781-782.

20. Wang C, Nieschleg E, Swerdoloff R, Behre HM, Hellstrom WJ, Gooren LJ et al. (2009) Investigation, treatment and monitoring of late-onset hypogonadism in males: ISA, ISSAM, EAU and ASA recommendations. J Androl. 30: 1-9.

21. Strong TD, Burnett AL, Champion HC, Bivalacqua TJ. (2008) Endothelium-specific gene and stem cell-based therapy for erectile dysfunction. Asian J Androl. 10: 14-22.

22. Yu W, Wan Z, QIu X, Chen Y, Dai Y. (2013) Resveratrol, an activator of SIRT1, restores erectile function in streptozotocininduced diabetes rats. Asian J Androl 15 (5): 646 - 651.

23. Sahan A, Akbal C, Tavukcu H, Cevik O, Cetinel S, Sekerci C. (2020) Melatonin prevents deterioration of erectile function in streptozotocin-induced diabetic rat via sirtuin-1 expression. Andrologia. 52 (3); 39.

24. Cummings MH, Meeking D, Warburton F, Alexander WD. (1997). The diabetic male's perception of erectile dysfunction. Practical Diabetes International. 14: 100-102.

25. U.S. Census Bureau, 2012 Population Estimates and 2012 National Projections.

26. Ezeude CM, Ezeude AM, Young EE, Oguejiofor OC, Bakari AG. (2020) Correlates of Erectile Dysfunction in Nigerian Men with Type 2 Diabetes Mellitus: Experience from a Tertiary Health Center. Journal of Diabetes Mellitus, 10, 182-201.

27. Zigmond AS, Snaith RP. (1983). "The hospital anxiety and depression scale”. Acta Psychiatrica Scandinavica. 67: 361-370.

28. Rosen RC, Cappelleri JC, Smith MD, Lipsky J, Pena BM. (1999). Development and Evaluation of an abridged, 5-item version of The International Index of Erectile Function (IIEF) as a diagnostic tool for erectile dysfunction. Int J Impot Res. 11:319-326.

29. Prader A. (1966). Testicular size: Assessment and Clinical Importance. Triangle. 7: 240-243.

30. Bhasin S, Cunningham GR, Hayes FJ, Matsumoto AM, Synder PJ et al. (2006). Testosterone therapy in adult men with androgen deficiency syndromes: An Endocrine Society Clinical Practice Guideline. J Clin Endocrinol Metab. 91: 1995-2010. 
31. Giugliano F, Maiorino M, Bellastella G, Gicchino M, Giugliano D et al. (2010). Determinants of Erectile Dysfunction in Type 2 Diabetes. Int J Impot Res. 23: 204-209.

32. Sharif F, Asghari M, Jaberi Y, Salehi O, Mirzamohammadi F. (2012). Independent predictors of Erectile dysfunction in Type 2 Diabetes Mellitus: Is it true what they say about Risk factors? ISRN Endocrinol. 2012: 502353.

33. Adebusoye LA, Olapade-Olaopa OE, Ladipo MM, Owoaje E. (2012). Prevalence and Correlates of Eredtile Dysfunction among Primary Care Clinic Attendees in Nigeria. Glob J Health Sci. 4: 107177.

34. Gooren LJ. (2009). Late-onset hypogonadism. Front Horm Res. 37:62-73.

35. Ahn TY, Lee SW, Hong JH, Park NC, Kim JJ et al. (2007) Prevalence and risk factors of erectile dysfunction in Korean men: Results of an epidemiological study. J Sex Med. 4: 1269-1279.
36. Ogbera AO, Chinenye S, Fasanmade O, Ajala W. (2011). Hypogonadism and Subnormal Total testosterone Levels in Men with Type 2 Diabetes Mellitus. Journal of the College of Physicians and Surgeons Pakistan. 21: 146-152.

37. Doumas M, Doumas S. (2006) The Effect of Antihypertensive Drugs on Erectile Function: A Proposed Management Algorithm. $J$ Hypertens. 8:359-363.

38. Betancourt-Albretch M, Cunningham GR. (2003) Hypogonadism and diabetes. Int J Impot Res 15, Suppl 4, S14 - S20.

39. El Saghier EOA, Shebi SE, Fawzy OA, Eltayeb IM, Bekhet LMA et al. (2015). Androgen Deficiency and Erectile Dysfunction in patients with Type 2 Diabetes. Clinical Medicine Insights: Endocrinology and Diabetes. 8; 55-62.

40. Talukder SK, Afsana F, Latif ZA, Pathan F, Ashrafuzzaman SM et al. (2011). Clinical and Biochemical Assessment of Hypogonadism in Type 2 Diabetic Men. Birdem Med J. 1: 3-9.

\section{APPENDIX 1}

\section{HOSPITAL ANXIETY AND DEPRESSION SCALE (HADS)}

This questionnaire has been designed to help you explain to your clinicians how you have been feeling.

Read each item below and indicate which comes closest to how you have been feeling in the past week. Ignore the numbers printed at the side. Don't take too long over your replies; your immediate reaction to each item will probably be more accurate than a long, thought-out response.

\section{DEPRESSION SCALE}

A. Still enjoying the things i used to enjoy:

0 - Definitely as much

1- Not quite so much now

2- Only a little

3- Hardly at all

B. I can laugh and see the funny side of things:

0 - As much as I always could

1- Not quite so much now

2- Definitely not so much now

3- Not at all

\section{I feel cheerful:}

0 - most of the time

1- Some times

2- Not often

3-Never

D. I feel as if I am slowed down:

0 - Not at all

1- Sometimes

2- Very often

3- Nearly all the time

E. I have lost interest in my appearance:

0 - I take just as much care as ever

1- I may not take quite as much care

2- I don't take as much care as I should

3- Definitely

F. I look forward with enjoyment to things:

0 - As much as I ever did

1- Rather less than I used to

2- Definitely less than I used to

3- Hardly at all

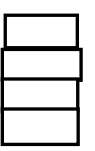

G. I can enjoy a good book or radio or television programme:

0 - Often

1- Sometimes

2- Not often

3- Seldom

TOTAL SCORING:

$<8=$ No Depression 
$>8=$ Depression

\section{ANXIETY SCALE}

A. I feel tense or "wound up":

0 - Not at all

1- From time to time, occasionally

2- A lot of the time

3- Most of the time

B. I get a sort of frightened feeling as if something awful is about to happen:

0 - Not at all

1- A little but it doesn't worry me

2- Yes, but not too badly

3- Very definitely and quite badly

C. Worry thoughts go through my mind:

0 - Only occasionally

1- From time to time but not too often

2- A lot of the time

3- A great deal of the time

D. I can sit at ease and feel relaxed:

0- Definitely

1- Usually

2- Not often

3- Not at all

E. I get a sort of frightened feeling like 'butterflres inl the stomach:

0 - Not at all

1- Occasionally

2- Quite often

3- Very often

F. I feel restless as if I have to be on the move:

0 - Not at all

1- Not very much

2- Quite a lot

3- Very much indeed

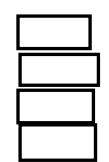

G. I get sudden feeling of panic:

0 - Not at all

1 - Not very often

2- Quite often

3- Very often indeed

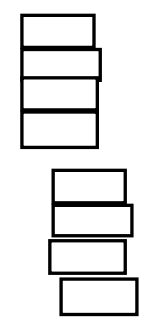

TOTAL SCORE:

$<8=$ No Anxiety

$>8=$ Anxiety

\section{APPENDIX 2}

\section{INDIVIDUAL ITEMS FROM THE INTERNATIONAL INDEX OF ERECTILE}

\section{FUNCTION (IIEF) QUESTIONNAIRE AND RESPONSE OPTIONS}

Circle the most appropriate Response option for each question

Question

Response options

(All questions are preceded by "Over the past 4 weeks")

1. How often were you able to get an erection during sexual activity?
$0 \square \square$ No sexual activity
$1 \square \square$ Almost never/never
$2 \square \square$ A few times (much less than half the time)
$3 \square \square$ Sometimes (about half the time)
$4 \square \square$ Most times (much more than half the time)
$5 \square \square$ Almost always/always

2. When you had erections with sexual stimulation, how often were your erections hard enough for penetration?

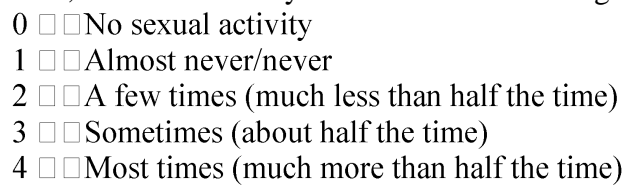


$5 \square \square$ Almost always/always

3. When you attempted sexual intercourse, how often were you able to penetrate (enter) your partner?

$0 \square \square$ Did not attempt intercourse

$1 \square \square$ Almost never/never

$2 \square \square$ A few times (much less than half the time)

$3 \square \square$ Sometimes (about half the time)

$4 \square \square$ Most times (much more than half the time)

$5 \square \square$ Almost always/always

4. During sexual intercourse, how often were you able to maintain your erection after you had penetrated (entered) your partner?

$0 \square \square$ Did not attempt intercourse

$1 \square \square$ Almost never/never

$2 \square \square$ A few times (much less than half the time)

$3 \square \square$ Sometimes (about half the time)

$4 \square \square$ Most times (much more than half the time)

$5 \square \square$ Almost always/always

5. During sexual intercourse, how difficult was it to maintain your erection to completion of intercourse?

$0 \square \square$ Did not attempt intercourse

$1 \square \square$ Extremely difficult

$2 \square \square$ Very difficult

$3 \square \square$ Difficult

$4 \square \square$ Slightly difficult

$5 \square \square$ Not difficult

6. How many times have you attempted sexual intercourse?

$0 \square \square$ No attempts
$1 \square \square$ One to two attempts
$2 \square \square$ Three to four attempts
$3 \square \square$ Five to six attempts
$4 \square \square$ Seven to ten attempts
$5 \square \square$ Eleven + attempts

7. When you attempted sexual intercourse, how often was it satisfactory for you?

$0 \square \square$ Did not attempt intercourse

$1 \square \square$ Almost never/never

$2 \square \square$ A few times (much less than half the time)

$3 \square \square$ Sometimes (about half the time)

$4 \square \square$ Most times (much more than half the time)

$5 \square \square$ Almost always/always

8. How much have you enjoyed sexual intercourse?

$$
\begin{aligned}
& 0 \square \square \text { No intercourse } \\
& 1 \square \square \text { No enjoyment } \\
& 2 \square \square \text { Not very enjoyable } \\
& 3 \square \square \text { Fairly enjoyable } \\
& 4 \square \square \text { Highly enjoyable } \\
& 5 \square \square \text { Very highly enjoyable }
\end{aligned}
$$

9. When you had sexual stimulation or intercourse, how often did you ejaculate?

$0 \square \square$ No sexual stimulation/intercourse

$1 \square \square$ Almost never/never

$2 \square \square$ A few times (much less than half the time)

$3 \square \square$ Sometimes (about half the time)

$4 \square \square$ Most times (much more than half the time)

$5 \square \square$ Almost always/always

10. When you had sexual stimulation or intercourse, how often did you have the feeling of orgasm or climax?

$$
\begin{aligned}
& 1 \square \square \text { Almost never/never } \\
& 2=\text { A few times (much less than half the time) } \\
& 3=\text { Sometimes (about half the time) } \\
& 4=\text { Most times (much more than half the time) } \\
& 5=\text { Almost always/always }
\end{aligned}
$$

11. How often have you felt sexual desire?

$$
\begin{aligned}
& 1=\text { Very low/none at all } \\
& 2=\text { Low } \\
& 3=\text { Moderate } \\
& 4=\text { High } \\
& 5=\text { Very high }
\end{aligned}
$$

12. How would you rate your level of sexual desire?

$$
1=\text { Very dissatisfied }
$$


2 = Moderately dissatisfied

$3=$ About equally satisfied and dissatisfied

$4=$ Moderately satisfied

$5=$ Very satisfied

13. How satisfied have you been with your overall sex life?

$$
\begin{aligned}
& 1=\text { Very low } \\
& 2=\text { Low } \\
& 3=\text { Moderate } \\
& 4=\text { High } \\
& 5=\text { Very high }
\end{aligned}
$$

14. How satisfied have you been with your sexual relationship with your partner?

$$
\begin{aligned}
\text { I } & =\text { Very low } \\
2 & =\text { Low } \\
3 & =\text { Moderate } \\
4 & =\text { High } \\
5 & =\text { Very high }
\end{aligned}
$$

15. How do you rate your confidence that you could get and keep an erection?

$$
\begin{aligned}
& 1=\text { Very low } \\
& 2=\text { Low } \\
& 3=\text { Moderate } \\
& 4=\text { High } \\
& 5=\text { Very high }
\end{aligned}
$$

TOTAL SCORE $=$

$\begin{array}{lc}\text { No ED } & =\text { Score of }>26 \\ \text { ED } & =\text { Score of }<25 \\ \text { Mild ED } & =17-25 \\ \text { Moderate ED } & =11-16 \\ \text { Severe ED } & =6-10\end{array}$

